\title{
The Characteristics of the Seafloor Massive Sulfide Deposits at the Hakurei Site in the Izena Hole, the Middle Okinawa Trough
}

\author{
Ryoto Yoshizumi, Youko Miyoshi, and Jun-ichiro Ishibashi
}

\begin{abstract}
The seafloor massive sulfide (SMS) deposits, which were found in the Izena Hole, the middle Okinawa Trough, show two modes of occurrence, namely, large sulfide mounds on the seafloor and massive sulfide bodies beneath sediments. A $610-\mathrm{cm}$ long sequence of alternating beds of sediment and ore layers was drilled to investigate the lower ore body, at high rates of core recovery (average $64 \%$ ), at the northern part of the Hakurei Site in the Izena Hole, the middle Okinawa Trough. Observation on polished sections of the core samples under reflection microscope indicates that the ores $(18-166 \mathrm{cmbsf}(\mathrm{cm}$ below seafloor)) above the sediment layer (166-221 cmbsf) are porous and contain acicular barite and globular sphalerite with small barite inclusions. These textures are considered to have formed as a result of rapid cooling. On the other hand, ores (221-510 cmbsf) below the sediment layer (166-221 cmbsf) had a massive layer of sphalerite and galena on top (black ore), a middle layer of pyrite and chalcopyrite-rich layer (yellow ore) and a bottom layer of sphalerite and large barite.
\end{abstract}

\section{Keywords}

Hydrothermal activity - Okinawa Trough • Seafloor Massive Sulfide deposit

- Sedimented rift

\subsection{Introduction}

Submarine hydrothermal activity in the middle Okinawa Trough was first discovered at the JADE site in the Izena Hole (Halbach et al. 1989). Although the numbers of seafloor massive sulfide (SMS) deposits found in arc-backarc systems are less numerous than those found in mid-ocean ridge systems, arc-backarc systems are associated with

R. Yoshizumi $(\bowtie)$

Department of Earth and Planetary Science, Graduate School of Science, The University of Tokyo, 7-3-1 Hongo, Bunkyo-ku, Tokyo 113-0033, Japan

e-mail: yoshizumi@eps.s.u-tokyo.ac.jp

Y. Miyoshi • J.-i. Ishibashi

Department of Earth and Planetary Sciences, Graduate School of Science, Kyushu University, 6-10-1 Hakozaki, Higashi-ku, Fukuoka 812-8581, Japan larger SMS deposits with higher concentrations of elements those are often enriched in epithermal environment associated with arc magmas (e.g., $\mathrm{Au}, \mathrm{Ag}, \mathrm{Pb}, \mathrm{As}, \mathrm{Sb}$ ) (Ishibashi and Urabe 1995; Herzig and Hannington 1995, 2000; Urabe et al. 2009). SMS deposits in arc-backarc systems are generally considered as modern analogue for volcanogenic massive sulfide (VMS) deposits of arcaffinity which are represented by Kuroko type deposits (Halbach et al. 1989).

Most of SMS deposits around Japan are distributed along Okinawa Trough basin and Izu-Ogasawara Arc. SMS deposits in the Okinawa Trough contain, on average, high concentrations of $\mathrm{Pb}, \mathrm{Zn}, \mathrm{Sb}, \mathrm{As}$ and $\mathrm{Ag}$ (Glasby and Notsu 2003). Deep-sea hydrothermal fields in the Okinawa Trough are unique among other back-arc basins in western and southwest Pacific because of the sedimented nature of the rifted basin. Recently, seafloor drilling during Integrated Ocean Drilling Program Expedition 331 revealed sulfide 
mineralization associated with hydrothermally altered sediment at two drilled sites, 100 and $450 \mathrm{~m}$ east of a hydrothermal mound at the Iheya-North hydrothermal filed in the Mid-Okinawa Trough (Takai et al. 2011; Yeats et al. 2012; Ishibashi et al. 2013; Yeats and Hollis 2013). As the existence of sulfide ores beneath the seafloor has been reported by METI (2011) at the Hakurei Site in the Izena Hole, we conducted drilling at the rim of a sulfide mound to obtain core material composed of sulfide ores between sediment layers.

\subsection{Geological Setting}

The Okinawa Trough, which is located in the west side of the Ryukyu arc, is back-arc basin that extends $\sim 1,200 \mathrm{~km}$ from Kyushu to Taiwan island (Fig. 43.1a). According to Kimura (1990) and Sibuet et al. (1987), the Okinawa Trough has been formed by subduction of the Philippine Sea plate under the Eurasian continent since early Pleistocene (2-1.5 Ma).

The Izena Hole in the middle Okinawa Trough is located at about $110 \mathrm{~km}$ northwest from Okinawa Island (Figs. 43.1a, b). The water depth of the basin floor of the Izena Hole is $\sim 1,600 \mathrm{~m}$ (Fig. 43.1b). Mud and pumice have been deposited in the Izena Hole since middle Pleistocene (0.9-0.4 Ma), based on biostratigraphic data from calcareous nannofossil in unconsolidated mud (Kato et al. 1989).

The central abyssal hill of the Izena Hole is formed from dacite, and it is known that heat flow at the bottom of the Izena Hole is high (Kato et al. 1989; Halbach et al. 1989). At the center of the Izena Hole (Hakurei Site), the SMS deposits have been found at the Hakurei Site. The Hakurei Site is divided into the north, center and south parts (METI 2011). The target field of this study is located in the north part of the Hakurei Site.

\subsection{Material and Methods}

\subsubsection{Sampling}

Drilling was conducted using the exploration vessel Hakurei-Maru No.2 from May 31 to June 9, 2011 (Ishibashi et al., Chap. 42). According to METI (2011), the SMS deposits have been found in the north mound and underlying subseafloor. These ore deposits are separated by silt and pumice-rich sedimentary layer with a thickness of a few meters. As the shallow subseafloor deposits have been
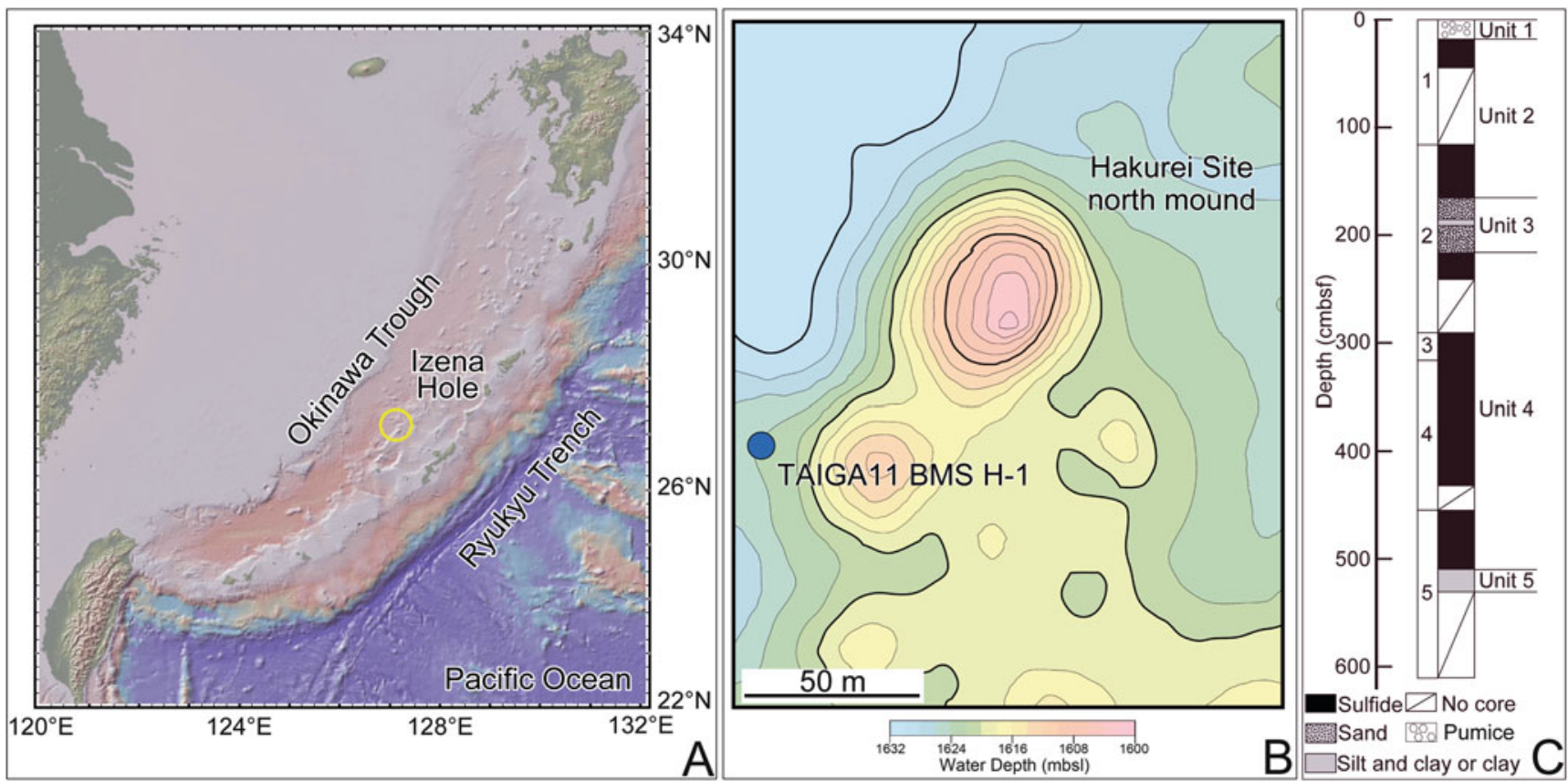

Fig. 43.1 Bathymetric maps of the drilling site and summary of drilled cores. (a) Location of the Izena Hole (yellow circle) in the Okinawa Trough in the northwest Pacific. (b) Bathymetric map of North mound of the Hakurei Site in the Izena Hole. The blue circle shows the location of the Hole TAIGA11 BMS H-1. (c) The core descriptions of TAIGA11 BMS H-1. Numbers of the left side of the column show the order of barrels used for drilling 
poorly studied, we drilled at the rim of the mound (TAIGA11 BMS H-1) for researching the subseafloor deposits by Benthic Multi-coring System (BMS) with five core barrels with a length of $2 \mathrm{~m}$. Each barrel was consecutively used to drill to obtain a 10-m long rock sequence. However, several core barrels were retrieved before full penetration. The depth of recovered core is estimated by the penetration depth of each core barrel. If the core length is shorter than the penetrated depth, the core depth was assigned by assuming that the recovered cores filled the core barrel from the top without any void space. The cores were cut into pieces and stored in plastic bags at room temperature after visual description on board.

\subsubsection{Sample Preparation and Analytical Methods}

For observations of mineral assemblages and textures, polished sections were prepared by embedding in epoxy resin and polishing with corundum powder and diamond paste. The images of the polished sections were obtained by an optical microscope (Nikon ECLIPSE E600POL E6TPM61) and a CCD camera (Zeiss AxioCam MRc 5). The scanning electron microscope with energy-dispersive spectroscopy (Hitachi S4500) was used to analyze chemical compositions of mineral grains. An accelerating voltage of $15 \mathrm{kV}$ was used for carbon-coated thin sections.

\subsection{Results and Discussion}

\subsubsection{Brief Description of Core Materials}

The drilling depth and recovery rate at the hole TAIGA11 BMS H-1 was $610 \mathrm{~cm}$ and about $64 \%$, respectively (Fig. 43.1c). The core column is divided into Unit 1-5 from those characteristics of sediments and ores (Fig. 43.1c). Unit 1 (0-18 cmbsf) was a $18-\mathrm{cm}$ thick layer of dark brown pumice. Unit 2 (18-166 cmbsf) was composed of porous dark ores with metallic luster. Unit 3 (166-221 cmbsf) was a clayish sediment layer including sand-granule with a thickness of $55 \mathrm{~cm}$. Unit 4 (221-510 cmbsf) was composed of massive ores, which color were changed from black to yellow and the black ore including white platy crystals. Unit $5(510-520 \mathrm{cmbsf})$ was a $10-\mathrm{cm}$ layer of gray clayish sediment.

\subsubsection{Mineral Assemblages and Textures}

Polished sections of cored ore sequences of Unit 2 (18-166 cmbsf) and Unit 4 (221-510 cmbsf) were observed every $\sim 10 \mathrm{~cm}$ interval using a reflection microscope, according to Matsukuma (1989) for mineral identification. In addition, SEM observations coupled to EDS analysis were conducted to verify the mineral identification.

As for Unit 2 (18-166 cmbsf), pyrite/marcasite (cream color; $\mathrm{FeS}_{2}$ ) and sphalerite (gray color; $\mathrm{ZnS}$ ) were abundant and found to be porous as indicated by black epoxy area (Fig. 43.2a). There were the aggregation of small grains of barite (dark gray; $\mathrm{BaSO}_{4}$ ) in sphalerite crystals (Fig. 43.2b). In addition, dendritic textures of tetrahedrite/ tennatite (greenish gray; $\left.\mathrm{Cu}_{10}(\mathrm{Fe}, \mathrm{Zn})_{2}(\mathrm{As}, \mathrm{Sb})_{4} \mathrm{~S}_{13}\right)$ were observed in sphalerite (Fig. 43.2c). As dendritic texture is generally known to form at low temperatures or under rapid cooling in sulfide chimneys (Ramdohr 1969; Ueno et al. 2003), dendritic tetrahedrite/tennatite might have formed under rapid cooling at the seafloor. As shown in Fig. 43.2d, the ore in bottom of Unit (116-166 cmbsf) was associated with pyrite/marcasite and acicular barite crystals.

On the other hand, as for Unit 4 (221-510 cmbsf), Fig. 43.2e-g shows sphalerite and galena (white; $\mathrm{PbS}$ ) with the minor occurrence of chalcopyrite (yellow; $\mathrm{CuFeS}_{2}$ ) and pyrite/marcasite in top of Unit4 (221-about $350 \mathrm{cmbsf}$ ), indicating that these ores were continuous. In addition, the minor occurrence of dendritic tetrahedrite/tennatite in sphalerite was found (Fig. 43.2g). Furthermore, sulfide ores of Unit $4(221-510 \mathrm{cmbsf})$ were different from Unit 2 (18-166 cmbsf) in terms of low porosity and large grains of metal sulfides. From the middle of Unit 4 (about 350-454 cmbsf), colloform pyrite/marcasite became predominant (Fig. 43.2h). Toward the bottom, mineral assemblages were shifted to pyrite/marcasite and chalcopyrite rich ores relatively (Fig. 43.2i). The arrows in Fig. 43.2j pointed out the co-occurrence of colloform chalcopyrite and pyrite. Sulfide ores in bottom of Unit4 (454-510 cmbsf) were also massive, and large euhedral cystals of barite were observed to be different from barite crystals in Unit 2 (18-166 cmbsf) (Fig. 43.2k). From these peterologic characteristics, five units were assigned and shown in Fig. 43.1c.

The transition of mineral assemblage along depth from black to yellow ores, which was found in the investigated core, is one of main characteristics of the Kuroko type deposits in northeast Japan formed by submarine hydrothermal activity between 17 and 11 Ma (Ohmoto 1996). The cause of the spatial segregation of black to yellow ores in Kuroko type deposits remains to be poorly understood, because various geological processes including burial metamorphism and denudation might have significantly alter the original peteolorogic and geochemical signatures. It is therefore important to investigate the SMS deposits at the Hakurei Site as a modern analogue of Kuroko type deposits. 

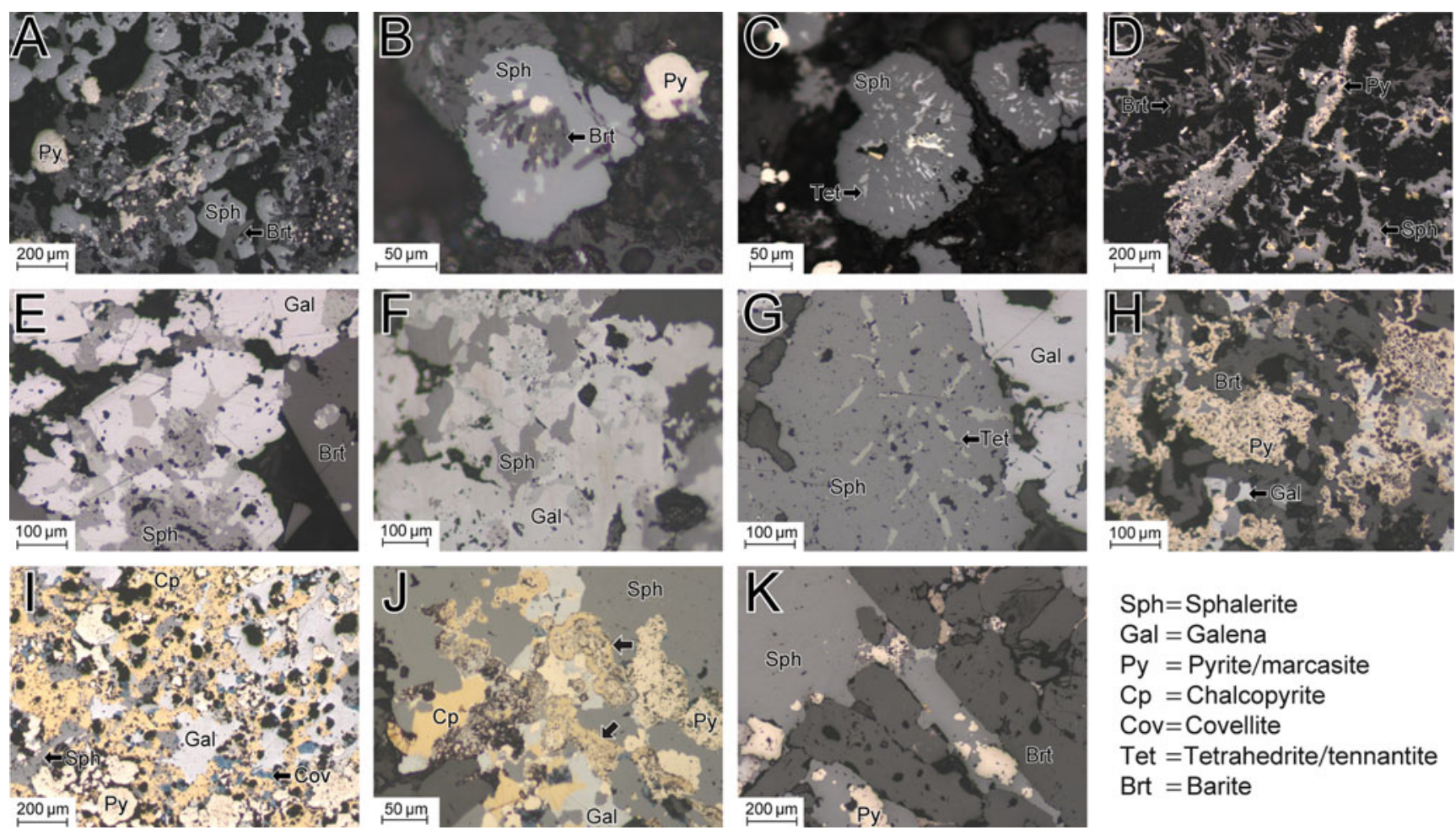

Fig. 43.2 Reflection microscopic images of TAIGA11 BMS H-1 cores. (a), (b) and (c) at $20 \mathrm{cmbsf}$, (d) at $147 \mathrm{cmbsf},(\mathbf{e})$ at $225 \mathrm{cmbsf}$, (f) at $324 \mathrm{~cm},(\mathbf{g})$ at $352 \mathrm{~cm},(\mathbf{h})$ at $369 \mathrm{cmbsf}$, (i) at $391 \mathrm{cmbsf}$, (j) at $400 \mathrm{cmbsf}$, and (k) at $496 \mathrm{cmbsf}$

\begin{abstract}
Acknowledgment We are grateful to Captain Morio Endo and crew of R/V Hakurei-Maru No.2, also to the team leader Tadashi Sato and members of the BMS operation team for their professional skill and careful consideration for collecting core samples during TAIGA11 cruise. Earlier version of the manuscript was significantly improved by constructive comments from a reviewer, Prof. Yohey Suzuki. We appreciate his great effort and encouragement. This study constitutes a part of the master thesis of the first author (R. Y.). R. Y. expresses sincerely gratitude to Prof. Tetsuro Urabe who supervised R. Y.'s master course study. This study was partially supported by TAIGA project as a Scientific Research on Innovative Areas by grants-in-aid for scientific research from Ministry of Education, Culture, Sports, Science and Technology of Japan (no. 20109006).
\end{abstract}

Open Access This chapter is distributed under the terms of the Creative Commons Attribution Noncommercial License, which permits any noncommercial use, distribution, and reproduction in any medium, provided the original author(s) and source are credited.

\section{References}

Glasby G, Notsu K (2003) Submarine hydrothermal mineralization in the Okinawa Trough, SW of Japan: an overview. Ore Geol Rev 23 (3):299-339. doi:10.1016/j.oregeorev.2003.07.001

Halbach P, Nakamura K, Wahsner M, Lange J, Sakai H, Käselitz L, Hansen R-D, Yamano M, Post J, Prause B (1989) Probable modern analogue of Kuroko-type massive sulphide deposits in the Okinawa Trough back-arc basin. Nature 338(6215):496-499. doi:10.1038/338496a0
Herzig PM, Hannington MD (1995) Polymetallic massive sulfides at the modern seafloor: a review. Ore Geol Rev 10(2):95-115

Herzig PM, Hannington MD (2000) Polymetallic massive sulfides and gold mineralization at mid-ocean ridges and in subduction-related environments. Handbook of marine mineral deposits, pp 347-368

Ishibashi J, Urabe T (1995) Hydrothermal activity related to arcbackarc magmatism in the western Pacific. In: Backarc basins: tectonics and magmatism, pp 451-495

Ishibashi J, Miyoshi Y, Inoue H, Yeats C, Hollis SP, Corona JC, Bowden S, Yang SY, Southam G, Masaki Y, Hartnett H, IODP Expedition 331 Scientists (2013) Subseafloor structure of a submarine hydrothermal system within volcaniclastic sediments: a modern analogue for 'Kuroko-type' VMS deposits. In: Proceedings of the 12th Biennial SGA Meeting, 12-15 August 2013, Uppsala, Sweden, ISBN 978-91-7403-207-9, pp 542-544

Kato Y, Nakamura K, Iwabuchi Y, Hashimoto J, Kaneko Y (1989) Geology and topography in the Izena Hole of the Middle Okinawa Trough-the results of diving surveys in 1987 and 1988. JAMSTECTR Deep Sea Res 5:163-182

Kimura M (1990) Genesis and formation of the Okinawa Trough, Japan. Mem Geol Soc Jpn 34:77-88

Matsukuma T (1989) Ore microscopy of the Kuroko ores in Japan. Institute of Mining Geology, Akita University, $88 \mathrm{p}$

Ohmoto H (1996) Formation of volcanogenic massive sulfide deposits: the Kuroko perspective. Ore Geol Rev 10(3-6):135-177. doi:10. 1016/0169-1368(95)00021-6

Ramdohr P (1969) The ore minerals and their intergrowths, 3rd edn. Pergamon, Oxford, English translation

Sibuet JC, Letouzey J, Barbier F, Charvet J, Foucher JP, Hilde TW, Kimura M, Chiao LY, Marsset B, Muller C (1987) Back arc extension in the, Okinawa Trough. J Geophys Res Solid Earth 92 (B13):14041-14063. doi:10.1029/JB092iB13p14041 
Takai K, MJ. Mottl, SH. Nielsen, The Expedition 331 Scientists (2011) Proceedings of IODP, 331: Tokyo (Integrated Ocean Drilling Program Management International, Inc.). doi:10.2204/iodp.proc.331.2011

The Ministry of Economy, Trade and Industry (METI) (2011) Midterm report of the activity during the first stage of development program for seafloor hydrothermal deposits (in Japanese)

Ueno H, Hamasaki H, Murakawa Y, Kitazono S, Takeda T (2003) Ore and gangue minerals of sulfide chimneys from the North Knoll, Iheya Ridge, Okinawa Trough, Japan. JAMSTEC J Deep Sea Res 22:49-62

Urabe T, Iizasa K, Ishibashi J (2009) The latest frontiers of earth science and its application to mineral exploration (part 1) submarine hydrothermal deposits as modern analogy. Shigen Chishitsu 59(1):43-72 (in Japanese with English abstract)

Yeats C, Hollis SP (2013) Actively forming Kuroko-style massive sulfide mineralisation and hydrothermal alteration at Iheya North, Okinawa Trough. Goldschmidt 2013, Florence, Italy, 25th-30th August

Yeats C, Hollis S, Corona JC, Expedition 331 Shipboard Scientific Party (2012) Actively forming Kuroko-style massive sulfide mineralization and hydrothermal alteration at Iheya North, Okinawa Trough-key petrological results of IODP Expedition 331. Abstract, 34th International Geological Congress, Brisbane, August $5-10,2012$ 